\title{
Astronomy heritage for education
}

\section{Magda Stavinschi}

\section{Astronomical Institute of the Romanian Academy}

\section{Bucharest, Romania}

E-mail: magda_stavinschi@yahoo.fr

We are celebrating four centuries since Galileo directed a telescope for the first time to the sky, when we recall the line of astronomy since its beginnings.

There are chapters in history very well known throughout the world, just as there are also very many which have been forgotten or which are totally unknown because of the political or geographical zone they belong to.

It is important that the young generation should know that the present discoveries of the universe are not only the fruits of top technologies but also the corollary of the observations and researches carried out throughout the globe for millennia.

As the sky belongs to all of us, so the cultural patrimony on the Earth.

Thus, the young people will be able to understand better the efforts of humanity throughout time, to know better the progress registered in their own country and to be more careful with the conservation of the cultural patrimony, in general, and of the astronomy one, in particular because the ignorance of these facts leads not only to destruction, but also to the alteration of future humanist thinking.

The "internet" generation must be trained to use the computers both for their own researches and for the capitalization and storage of the information concerning the world astronomy past.

\section{One of the cornerstones projects of IYA2009}

\section{IAU/UNESCO Astronomy and World Heritage: universal treasures}

UNESCO and IAU are working together to implement a research and education collaboration as part of UNESCO's thematic initiative, Astronomy and World Heritage. The main objective is to establish a link between science and culture on the basis of research aimed at acknowledging the cultural and scientific values of properties connected with astronomy. This program provides an opportunity to identify properties related to astronomy located around the world, to preserve their memory and save them from progressive deterioration. Support from the international 
community is needed to implement this activity and to promote the recognition of astronomical knowledge through the nomination of sites that celebrate achievements in science.

On October 30, 2008 was signed a Memorandum of Understanding between UNESCO and IAU, which became the foundation of a cornerstone project of IYA20009.

The world-famous UNESCO World Heritage Convention is renowned for its work protecting and promoting sites that celebrate the heritage of humanity ${ }^{1}$.

New WG on Astronomy and World Heritage was founded under the chairmanship of Prof. Clive Ruggles $^{2}$. This WG will officially recognize, promote and preserve astronomical sites that are of outstanding significance to humankind.

\section{SEAC}

Another international body among whose objectives is the same goal of identifying and protecting the astronomical patrimony is Société Europénne l'Astronomie en Culture" - SEAC . It is a professional association of scientists working in the field of Astronomy in Culture or Anthropological Astronomy, including the interdisciplinary disciplines of Archaeoastronomy and Ethnoastronomy.

However, researchers in nearby fields of science like History of Astronomy, Mythology, Spatial Archaeology or Cosmology are also welcomed in the SEAC.

During SEAC XIIth Conference - 2004, a WG was set up (to take care about) to look after the archaeoastronomical heritage ${ }^{4}$.

The main goal of this WG is the identification of objects of astronomical value. A first classification could include: sites, sanctuaries, buildings, sundials, instruments, drawings, ancient books. Among the necessary data we will need, are: coordinates of place, data of founding/constructing, the owner, some photos, description, bibliography. All this can be included in a data bank which will be posted on the WG site 5 .

\section{Education}

As long as the young people are not systematically informed about the universe, do not know the stages when it was discovered and do not know their own astronomical history they do not know how to preserve their astronomical heritage, to interpret the knowledge they have, not only for the progress of astronomy, but also for that of science, in general.

I am speaking from our Romanian experience.

Although the civilization on the Romanian territories is very old (evidences from Neolithic), a series of factors hindered a good conservation of the knowledge accumulated along the centuries:

\footnotetext{
${ }^{1}$ UNESCO Contact: Anna SIDORENKO-DULOM, Coordinator Thematic Initiative "Astronomy and World Heritage" UNESCO World Heritage Centre

${ }^{2}$ Emeritus Prof. of Archaeoastronomy at the Univ. of Leicester, president of the IAU's Commission 41

${ }^{3}$ European Society for Astronomy in Culture

${ }^{4}$ Chair: Magda Stavinschi

${ }^{5}$ http://www.archeoastronomy.org/heritage/index.html
} 
- natural calamities (earthquakes, floods, fire, etc.)

- inadequate conservation: nonprofessional restoration of sanctuaries, paintings, etc.

- inadequate storing places (humidity, dust, rodents, moths);

- inadequate urbanism rules

- political reasons (invasions, wars, internal struggles).

These are only a few factors which have affected the preservation of the astronomy heritage. There were others, as well, due to the special situation during the totalitarism, namely the denature of origins according the interest of the moment (Slavism, Latinity, etc.). The past was avoided, in order to emphasize the Leader's performances, etc.

What were the consequences?

- $\quad$ lack of systematic studies concerning the history of science (and, obviously, of astronomy);

- $\quad$ lack of interest in storing scientific evidences;

- $\quad$ erroneous mentality as regards their role in the progress of the modern society.

However, scientific education leads to an improvement of research, the stimulation of curiosity, a knowledge as complete as possible of the astronomical culture evolution, as a part of civilisation, to a correct interpretation of the materials studied and last, but not least to an adequate strategy regarding the future of our planet.

Naturally, this education starts from a very early age, even from the first school years. There are several ways in which children can be educated in the spirit of knowledge and patrimony preservation:

Everything has to be achieved through learning.

It is very important that the national and world history be known in the first place in order to be able to identify the period and the context in which the patrimony objects were made.

Popular traditions concerning the sky have to be known as well. They can be found in the most unexpected places, e.g.: national costumes, houses, Easter eggs, legends, stories.

Obviously, when we refer to the astronomy heritage, astronomy has to be known very well, at least at general level, as well as the relation between astronomy and the other sciences (mathematics, physics, chemistry, biology, etc), or the relation between astronomy and culture (literature, music, heraldry, popular art, etc.)

If the knowledge about astronomy seems natural, one may wonder why its relation with the other sciences has to be known as well, and also its relation with culture under all its aspects. All this has to be done in order:

Oto be able to understand the evolution of this old science in the period when astronomical instruments did not even exist 
to become aware of the role of imagination and creativity in cosmos knowledge (don't forget: 2009 was also the European Year of Creativity and Innovation)

to come to know better the history of their native places through the history of astronomy (as each place on Earth has its own history, naturally integrated into world history)

Oto understand the future of the society they belong to.

Which would be the next steps?

The pupils have to bring their own contribution to the identification of this patrimony.

I had an uncle, who was a history teacher but was also very keen on archeology. The region where he lived was full of vestiges of the Roman society dating from the beginning of the first millennium. His pupils knew that if they brought him an object from that epoch they would pass their exams. It was not a simple thing: they had to identify it themselves \& to tell the story of the respective epoch). Many of his pupils became scientists

\section{Data Bank}

At present considerable steps are taken for the creation of a data bank which should include all kinds of patrimony objects.

The pupils can participate directly in the identification and the making of the data bank, especially as they do not lack calculation technique. They have computers, cameras; the only thing they have to do is to fill in to the best the tables where these objects can be included

\section{Human Models}

We consider that the analytical and critical analysis of the work left by the predecessors of Astronomy will be beneficial to the education of the new generations, to the rekindling and redefinition of the existential landmarks of the confused ones, who have to pass first of all through the relatively simple, but necessary phase of hope revival.

A society without models and ideals is often doomed to failure and to the chaotic dissipation of its energies.

The channeling and redirecting of the latter ones is not accomplished through directives, recipes and ideologies, but first of all through the capitalization of one's personality and talent.

Paradoxically, the society atomized through individualism recovers starting with the individual.

From Astronomy's predecessors we have to learn not only ideas, principles and values, but first and foremost the way in which these can be translated into a way of life, for the spiritual development of man, community, nation, mankind.

It is very important that the history of ideas be studied very attentively. The largest part of the knowledge on the universe has been obtained through observation, thinking, debate and much later by means of instruments 
The knowledge about the relationships which have existed between Science and Faith cannot be neglected in an epoch of information boom and of the proliferation of ideas such as the creationist ones. It is a sad that at the celebration of four centuries elapsed since the first observation of the sky with an astronomical instrument, the general public remembers Galileo Galilei as a victim of the Church than through his discoveries which had a great impact on science, or better said, which laid the basis of modern scientific astronomy. We have to tell the general public how much was true and how much was myth in the history of the astronomical thinking evolution.

\section{Astronomy vs. Astrology}

In the same context we can talk about the relation Astronomy-Astrology. They have a common history which has to be known both by the specialists and by those we want to inform and educate.

Numerous traditions and applications employing astrological concepts have arisen since its earliest recorded beginnings in the 3rd millennium BC. Astrology has played an important role in the shaping of culture, early astronomy, the Vedas, the Bible, and various disciplines throughout history.

There were numerous astronomical personalities who did horoscopes, e.g. Tycho Brahe, Kepler, Galilei. Let us not forget Kepler's famous metaphor comparing astrology to the 'foolish daughter' of the 'wise mother' (astronomy)

Consequently we have to know very well the motives and the context in which such a professional of astronomy was able to serve astrology, as well. To avoid such a delicate issue can only harm science, society and the latter one's progress.

\section{Natural astronomy heritage}

However, astronomy heritage does not mean only the preservation of the man made constructions. Our very planet has to be preserved, especially its atmosphere. An increasingly aggressive pollution will lead to a situation similar to the one on Venus, when life will no longer be possible.

The dark sky is another extremely serious problem of mankind. The fast increasing use of artificial light will have unthinkable repercussions on biological life and on the knowledge about the environment.

Darkness is a natural patrimony of the world which has to be kept.

Moreover, we are afraid of meteorites fall, but we do not pay enough attention to the danger posed to Earth by the numerous experiments made by man.

\section{Globalisation}

Finally, we cannot talk about the relation between astronomy heritage and education without mentioning a situation which seems to scare the present world, namely globalization. 
If one looks at the identity of each planet in a stellar system, of several stellar systems in a galaxy and the list can go on, one can also find examples in nature where identity does not necessarily mean the annulment of globalization.

At the beginning of civilisations the only barriers among various populations were the distances which could be crossed with great difficulty. Thus, various regions developed various cultures which were nevertheless very similar. Today distance does not matter any more. Communication has become a trivial thing. Globalisation seems to be the universal law of the modern world. And here comes astronomy heritage which emphasizes the characteristics of each ethnic group; their calendars were different, they had different sky legends, different cosmic symbols. And yet astronomical knowledge was on the whole unique.

Here are lessons which astronomy heritage can give to the new generations and why not, to the political world, which we can only hope that is thinking about a good future of mankind.

Finally, we come to an inevitable conclusion: one cannot have a future without knowing one's past. 